\title{
Clinical features, concurrent disorders, and survival time in cats with suppurative cholangitis-cholangiohepatitis syndrome
}

\author{
Sharon A. Center, DVM*; John F. Randolph, DVM; Karen L. Warner, BS; James A. Flanders, DVM; H. Jay Harvey, DVM
}

Department of Clinical Sciences, College of Veterinary Medicine, Cornell University, Ithaca, NY

*Corresponding author: Dr. Center (sac6@cornell.edu)

https://doi.org/10.2460/javma.20.10.0555

\section{OBJECTIVE}

To characterize clinical features, comorbidities, frequency of bacterial isolation, and survival time in cats with suppurative cholangitis-cholangiohepatitis syndrome (S-CCHS).

\section{ANIMALS \\ 168 client-owned cats with S-CCHS.}

\section{PROCEDURES}

Data were prospectively (1980 to 2019) collected regarding clinical features, comorbidities, bacterial infection, illness duration, and treatments. Variables were evaluated for associations with survival time.

\section{RESULTS}

Median age of cats was 10.0 years, with no breed or sex predilection observed. Common clinical features included hyporexia (82\%), hyperbilirubinemia (80\%), lethargy (80\%), vomiting (80\%), jaundice (67\%), weight loss (54\%), and hypoalbuminemia (50\%). Comorbidities included extrahepatic bile duct obstruction (53\%), cholelithiasis (42\%), cholecystitis (40\%), and ductal plate malformation (44\%) as well as biopsy-confirmed inflammatory bowel disease $(60 / 68$ [88\%]) and pancreatitis (41/44 [93\%]). Bacterial cultures were commonly positive (69\%) despite prebiopsy antimicrobial administration in most cats. Of surgically confirmed choleliths, diagnostic imaging identified only $58 \%$. Among 55 cats with "idiopathic pancreatitis," 28 (51\%) were documented to have transiting choleliths, and 20 had pancreatic biopsies confirming pancreatitis. Cholelithiasis (with or without bile duct obstruction) and cholecystectomy were associated with survival advantages. Survival disadvantages were found for leukocytosis, $\geq 2$-fold increased alkaline phosphatase, and hyperbilirubinemia. Cholecystoenterostomy had no survival impact. Cats with ductal plate malformations were significantly younger at diagnosis and death than other cats. Chronic treatments with antimicrobials, S-adenosylmethionine, and ursodeoxycholic acid were common postbiopsy.

\section{CLINICAL RELEVANCE}

$\mathrm{S}-\mathrm{CCHS}$ in cats was associated with bacterial infection and various comorbidities and may be confused with pancreatitis. Surgically correctable morbidities (ie, cholecystitis, cholecystocholelithiasis) and cholecystectomy provided a significant survival advantage.

M ost necroinflammatory liver disorders affecting the domestic cat target the portal tract, often with a duct-centric orientation. These conditions qualify as cholangitis or, if inflammatory infiltrates also spill across the limiting plate of the portal tract, cholangiohepatitis; nomenclature refers to this feline disease pattern as a cholangitis-cholangiohepatitis syndrome (CCHS). Histologic patterns of feline CCHS have been classified on the basis of the predominant cellular infiltrate (neutrophilic or suppurative vs mononuclear [lymphocytic, Iymphoplasmacytic] or nonsuppurative), with additional qualifiers characterizing bile duct involvement, extent of injury, and fibrosis (eg, bile duct hyperplasia, dilation, tortuos- ity, evolving ductopenia, and circumferential peribiliary fibrosis). ${ }^{1}$ In humans, nonsuppurative cholangitis includes a spectrum of bile duct changes involving lymphocytic inflammation with evolution of periductal sclerosing fibrosis and destructive cholangiopathy leading to ductopenia of an immunemediated pathogenesis. ${ }^{1}$ Similarly, nonsuppurative CCHS (NS-CCHS) in cats involves T-cell-mediated destructive cholangiopathy that progresses to loss of small- and medium-sized bile ducts with terminal ductopenia., ${ }^{2,3}$ Bacterial culture and molecular methods for bacterial detection rarely confirm infection in liver tissue or bile from cats with NS-CCHS. ${ }^{3}$ In contrast, feline suppurative CCHS (S-CCHS) is consid- 
ered to involve a bacterial origin although this histologic pattern also may develop secondary to acute or chronic mechanical bile flow obstruction. ${ }^{4}$ Whether S-CCHS associated with bacterial infection can gradually transform into NS-CCHS remains unknown.

A previously proposed scheme for characterization of CCHS differentiates neutrophilic cholangitis into acute and chronic categories. ${ }^{5}$ However, application of this classification scheme to a necropsy database of cats with cholangitis ( 7 with acute and 33 with chronic neutrophilic cholangitis) demonstrated broad overlap in clinical and clinicopathologic features as well as wide variability in severity of histologic lesions among liver sections from the same patient. ${ }^{6}$ Thus, this scheme had poor clinical and diagnostic utility. The histologic categorization of cholangitis in humans is simplified into suppurative and nonsuppurative forms and then further characterized by syndromic patterns. ${ }^{1}$ This straightforward approach for CCHS classification is preferred by the authors and has been employed in the present study.

Despite the impression that S-CCHS in cats is a grave disorder, information defining the clinical features, comorbidities (eg, cholelithiasis, extrahepatic bile duct obstruction [EHBDO], anatomic malformations of the biliary tree, inflammatory bowel disease [IBD], or pancreatitis), bacterial involvement, and survival time is limited to single-case reports, small case series, and necropsy-based studies. ${ }^{6-30}$ The purpose of the long-term (40-year) prospective study reported here was to definitively characterize the syndrome of feline S-CCHS.

\section{Materials and Methods}

\section{Case selection criteria}

Cats with S-CCHS were prospectively identified on the basis of histopathologic features of liver biopsy specimens with clinical data cataloged at the time of diagnosis over a 40-year interval (1980 to 2019) by one of the authors (SAC). All histologic sections were initially inspected by board-certified veterinary anatomic pathologists and residents in training and were concurrently evaluated by one of the authors (SAC) with extensive experience and expertise in hepatic histopathology. Tissues from all cases were also reinspected at the time of data analysis without knowledge of prior histologic characterization or clinical disease spectrum, to ensure consistent stringency of histologic inclusion criteria, as described in the companion manuscript. 31 Diagnosis of S-CCHS required a predominantly portal neutrophilic infiltrate with duct-centric orientation, with or without features consistent with EHBDO, cholangiocyte proliferation (ductular reaction), destructive cholangitis (ie, necrotic duct epithelium, irregular duct epithelial stratification or attenuation, and duct collapse or involution), or invasion of the limiting plate of the portal tract (ie, the interface between the portal adventia and adjacent periportal hepatic parenchyma) by inflammatory infiltrates. Definitive categorization of comorbidities was ascertained after reconciliation of histologic features and clinical information (history, physical examination findings, radiographic and ultrasound images, and gross observations at surgery or necropsy). Histologic features defining discrete comorbidities (EHBDO, cholelithiasis, cholecystitis, ductal plate malformation [DPM], IBD, and pancreatitis) were considered, as previously defined.31-33 Cats with CCHS that had a predominantly (> 50\%) nonsuppurative inflammatory infiltrate were excluded. All cats received standard-of-care medical and surgical treatments with owner consent.

Liver tissue was collected as diagnostic biopsy specimens $(n=140)$ from live cats, at the time of perioperative (within 24 hours after surgery) death (14), or by both procedures (14). Most antemortem samples were wedge surgical biopsy specimens, but 8 were ultrasound-guided 14- or 18-gauge needle core samples. Samples obtained by biopsy needle were required to collectively provide $\geq 15$ portal tracts for cats to be included in the study. Liver biopsy specimens were fixed in neutral-buffered $10 \%$ formalin, embedded in paraffin, sectioned at $5 \mu \mathrm{M}$, and routinely stained with H\&E and Masson trichrome stains.

\section{Medical record review}

Clinical records of cats that met histologic inclusion criteria were reviewed with owners and referring veterinarians to clarify duration of antecedent illness before definitive diagnosis of S-CCHS, pre- and postbiopsy treatments, and survival status. An organizational spreadsheet was used to standardize data collection, which included age, sex, reproductive status, antecedent illness duration, clinical signs (including hyporexia, vomiting, diarrhea, lethargy, and weight loss), concurrent illnesses (ie, diabetes mellitus, biopsy-confirmed IBD or pancreatitis, cholelithiasis, EHBDO, or cholecystitis), physical examination findings (pyrexia or rectal temperature $>39.2^{\circ} \mathrm{C}$, dehydration, hepatomegaly, jaundice, abdominal pain, or abdominal effusion), and results of clinicopathologic tests (CBC, serum biochemical profile, urinalysis, and routine coagulation [prothrombin time $\{\mathrm{PT}\}$ and $\mathrm{ac}-$ tivated partial thromboplastin time $\{$ aPTT $\}$ ] tests). Because various analyzers and reagents were used over the decades of study for biochemical profiling and coagulation tests, some data were converted to fold increases or decreases relative to reference intervals. Liver enzyme activity was converted to fold increase relative to the upper relevant reference limit. Prolonged coagulation times were converted to fold prolongation relative to the upper reference limit, with abnormal defined as $\geq 1$.2-fold prolongation and critical as $\geq 1.5$-fold prolongation. Coagulation tests were consistently evaluated against control tests of pooled citrated feline plasma.

Details recorded from findings of abdominal radiography included estimated liver size, liver contour (smooth or irregular), detection of radiodense foci consistent with mineralized choleliths, and suspected abdominal effusion. Details recorded from findings of abdominal ultrasonography included estimated liver size and marginal contours; suspected hepatic mass lesions; gallbladder volume, wall thick- 
ness, and luminal distention and nature of intraluminal cholecystic debris (organized, mineralized, or gravitational mobility); suspected extrahepatic bile duct tortuosity, distention, or intraluminal debris; prominent to distended hepatic duct and associated intraluminal debris or mineral densities; cystic structures or common bile duct diverticula suggestive of choledochal cyst or severe Caroli DPM; mesenteric Iymphadenopathy; and abdominal effusion. A board-certified veterinary radiologist reviewed all radiograph and ultrasound images at the time of case diagnostic evaluations. Surgical reports, if applicable, were reviewed for gross descriptions of the liver (size, color, surface irregularity, and marginal contours), gallbladder (suppleness, ability to express vs obstruction, and color), cystic duct, and extrahepatic or hepatic bile duct dilation or tortuosity; presence of choleliths (location, size, color, and number); evidence of gallbladder rupture or historic bile leakage; and surgical interventions (cholecystectomy, cholecystotomy, cholecystoenterostomy, choledochoenterostomy, or temporary bile duct stenting). Specifics of bacterial culture results are reported elsewhere. ${ }^{31}$ Cholelith analyses were completed in human medical stone analysis laboratories (ie, the Baylor University Urolithiasis Laboratory and Louis C. Herring Laboratory) and veterinary urolith laboratories (ie, the G. Ling Urolithiasis Laboratory at the University of California-Davis and the Minnesota Urolith Center at the University of Minnesota). Choleliths were classified as predominantly calcium carbonate, cholesterol, or pigmented stones by means of polarizing light microscopy, infrared spectroscopy, or x-ray crystallography. Other collected data included treatments before definitive diagnosis (eg, antimicrobials or glucocorticoid or other immunosuppressant medications), coexistent disease conditions, perioperative and postoperative antimicrobial administration, survival time after definitive diagnosis (days), and last recorded age (years) for survivors and nonsurvivors.

\section{Statistical analysis}

Data were examined for normal distribution by use of box-and-whisker plots and the Shapiro-Wilk test. Because most data were nonparametric, values were summarized as median (range) and 95\% $\mathrm{Cl}$. Cats were stratified for comparison of clinical signs, clinicopathologic parameters, and survival analyses on the basis of sex; presence or absence of jaundice, leukocytosis, or fever; and presence or absence of comorbidities, including EHBDO, cholelithiasis, cholecystitis, DPM, diabetes mellitus, biopsy-confirmed $\mathrm{IBD}$, and biopsy-confirmed pancreatitis, presence or absence of therapeutic surgical interventions (ie, cholecystectomy, biliary enteric anastomosis) and presence or absence of positive bacterial culture results. Two-by-two tables and the Fisher exact test were used to test the hypothesis that gender distribution would be equivalent ( $50 \%$ male and $50 \%$ female). Numbers of cats with specific clinical signs and hematologic abnormalities were determined and expressed as percentages. Biochemical features were tabulated with respect to relevant directional fold changes from the upper or lower reference limit. Clinicopathologic findings were summarized as the number and percentage of cats with a measured parameter above or below the upper or lower relevant reference limits. Because reference limits for hematologic parameters and certain biochemical analytes (BUN and serum creatinine, glucose, total protein, albumin, globulin, and cholesterol concentrations) were consistent, reported test values were directly evaluated and used for categorical comparisons. Data for liver enzyme activities and total bilirubin concentrations were transformed to the fold increase above the relevant upper reference limit for scatterplot display.

Selected hematologic and biochemical parameters were compared between cats surviving < and $>14$ days by means of the Wilcoxon rank sum test. When numerous comparisons were made, Bonferroni corrections were applied (ie, resulting in $P=0.015$ for hematologic parameters [PCV, leukocytosis, neutrophilia] and $P=0.006$ for biochemical parameters) for declaration of significant differences. KaplanMeier curves for survival time (days) after definitive diagnosis of S-CCHS were inspected for all cats and with the population stratified by presence or absence of jaundice, neutrophilia, leukocytosis, fever, abdominal pain, vomiting, weight loss, diarrhea, hepatomegaly, EHBDO (with and without cholelithiasis), cholelithiasis (with and without EHBDO), DPM, cholecystitis (with or without cholecystectomy), and cholelithiasis or EHBDO with or without cholecystoenterostomy (either cholecystoduodenostomy or cholecystojejunostomy). The impact of positive bacterial culture results on survival time is detailed in the companion report. ${ }^{31}$ Differences between groups in survival time were evaluated using the Gehan-Wilcoxon test as a measure of short-term survival and the log-rank test as a measure of longterm survival. Values of $P \leq 0.05$ were considered significant unless otherwise declared. Statistical analyses were performed with a statistical software program (Statistix 9; Analytical Software).

\section{Results}

\section{Animals}

Among cats with S-CCHS, there were 93 males (83 neutered and 10 sexually intact) and 75 females (71 neutered and 4 sexually intact), with no sex predilection $(P=0.40)$. Represented cat breeds included domestic shorthair ( $n=123$ ), domestic longhair (19), Siamese (10), Manx (3), Persian (2), Himalayan (2), British Shorthair (2), and 1 each of Abyssinian, Bengal, Burmese, Ocicat, Savannah, Sphinx, and Tonkinese. Median age was 10.0 years (range, 0.5 to 20.0 years). Cats with DPM were significantly ( $P \leq$ 0.02 ) younger (median age, 7.2 years; range, 0.5 to 20.0 years) than cats without this congenital deformity. Otherwise, no significant age differences were evident between groups (all $P \geq 0.20$; Supplemen-

\section{tary Table S1).}




\section{Clinical features}

Frequencies of clinical signs and physical examination findings were similar among categorical groups (Table 1). Median duration of clinical illness before definitive diagnosis of S-CCHS was 30 days (range, 1 to 1,460 days; Supplementary Table S1). Among comorbidities, the only significant difference $(P=0.03)$ was longer antecedent illness duration in cats with DPM compared with cats without DPM. Cats with cholelithiasis often displayed chronic recurrent or cyclic illness for weeks to months before definitive diagnosis. Some of these cats had sequential assessment of pancreatic specific biochemical tests implicating pancreatitis. Of 55 cats clinically suspected of having "idiopathic" pancreatitis, 28 (51\%) had transiting choleliths verified by sequential ultrasound examinations (performed by the same imager) or intraoperative surgical evaluation (ie, choleliths that were within the gallbladder neck, cystic duct, or common bile duct or were occluding the duodenal papilla).

Pertinent clinicopathologic findings were summarized (Table $\mathbf{2}$ and Figure $\mathbf{1}$ ). Of cats with neutrophilic leukocytosis, 22\% demonstrated band neutrophils. Frequent biochemical abnormalities included mild hypoalbuminemia, mild hyperglycemia, hyperbilirubinemia, and increased liver enzyme activities (alanine aminotransferase [ALT], aspartate aminotransferase [AST], alkaline phosphatase [ALP], and $\gamma$-glutamyltransferase [GGT]). Hyperbilirubinemia varied in magnitude, with a $\geq 2$-fold increase in 134 (80\%) cats and median fold increase of 11.9 (range, 0.3 to 74.5 ). There was wide variation in the magnitude of increased liver enzyme activity (Figure 1). The percentage of cats with increased liver enzyme activities was 88\% for ALT, 79\% for AST, $63 \%$ for ALP, and $73 \%$ for GGT, with $\geq 2$-fold increases noted for ALT (124/164 [76\%]), AST (65/119 [55\%]), $\operatorname{ALP}(72 / 164$ [44\%]), and GGT (75/132 [57\%]). Median (range) fold increase for ALT was 4.1 (0.2 to 56.8), for AST was 2.1 (0.2 to 95.7), for ALP was 1.7 (0.1 to 21.3), and for GGT was 2.7 (0 to 50.1).

Prolonged PT (median fold increase, 1.23; range, 1.04 to 2.40) and aPTT (median fold increase, 1.27; range, 1.06 to 4.99 ) occurred in 16 of 67 (24\%) and 27 of $66(41 \%)$ cats, respectively. Critically prolonged coagulation results ( $\geq 1.5$-fold above upper reference limit) were observed for PT in 6 of 16 (38\%) cats and for aPTT in 10 of 27 (37\%) cats. These cats were jaundiced and had been ill for $\geq 7$ days, usually with obstructive cholangiopathy (eg, EHBDO due to cholelithiasis or neoplasia). For 6 cats with prolonged clotting results retested after vitamin $\mathrm{K}_{1}$ administration, clotting times normalized. Most (95\%) jaundiced cats were treated with parenteral vitamin $\mathrm{K}_{1}$ before surgical intervention, irrespective of coagulation assessments. Of 159 cats given parenteral vitamin $\mathrm{K}_{1}$ (IM or SC), none had an adverse reaction. Two cats without preoperative coagulation assessments that did not receive parenteral vitamin $\mathrm{K}_{1}$ developed criti-

Table 1-Frequencies of clinical features in selected groups of cats with suppurative cholangitis-cholangiohepatitis syndrome.

\begin{tabular}{|c|c|c|c|c|c|c|c|c|c|}
\hline Group & Hyporexia & Lethargy & Vomiting & Jaundice & $\begin{array}{l}\text { Weight } \\
\text { loss }\end{array}$ & Pyrexia & $\begin{array}{l}\text { Large } \\
\text { liver }\end{array}$ & $\begin{array}{l}\text { Abdominal } \\
\text { pain }\end{array}$ & Diarrhea \\
\hline All cats $(n=168)$ & $138(82)$ & $134(80)$ & $134(80)$ & $113(67)$ & $90(54)$ & $73(43)$ & $57(34)$ & $39(23)$ & 32 (19) \\
\hline Jaundice $(n=113)$ & $96(85)$ & $94(83)$ & $88(78)$ & $113(100)$ & $62(55)$ & $49(43)$ & $49(43)$ & $30(27)$ & $16(14)$ \\
\hline Cholelithiasis $(n=71)$ & $61(86)$ & $61(86)$ & $64(90)$ & $51(72)$ & $32(45)$ & $31(44)$ & $26(37)$ & $23(32)$ & $13(18)$ \\
\hline Cholecystitis $(n=68)$ & $63(93)$ & $59(87)$ & $60(88)$ & $51(75)$ & $35(51)$ & $32(47)$ & $27(40)$ & $22(32)$ & $16(24)$ \\
\hline Cholecystectomy $(n=39)$ & $36(92)$ & $34(87)$ & $37(95)$ & $30(77)$ & $19(49)$ & $14(36)$ & $17(44)$ & $12(31)$ & $10(26)$ \\
\hline $\operatorname{DPM}(n=74)$ & $62(84)$ & $60(81)$ & $58(78)$ & $53(72)$ & $37(50)$ & $40(54)$ & $26(35)$ & $19(26)$ & $9(12)$ \\
\hline Biopsy-confirmed IBD* $(n=60)$ & $58(97)$ & $55(92)$ & $54(90)$ & $33(55)$ & $32(53)$ & $30(50)$ & $25(42)$ & $15(25)$ & $16(27)$ \\
\hline Biopsy-confirmed pancreatitis* $(n=41)$ & $34(83)$ & $36(88)$ & $35(85)$ & $25(61)$ & $26(63)$ & $27(66)$ & $17(41)$ & $17(41)$ & $6(15)$ \\
\hline Positive culture result* $(n=93)$ & $80(86)$ & $81(87)$ & $80(86)$ & $62(67)$ & $53(57)$ & $45(48)$ & $32(34)$ & $31(33)$ & $23(25)$ \\
\hline
\end{tabular}

*Only 68, 44, and 135 cats, respectively, were tested for IBD or pancreatitis or underwent bacterial culture.

$\mathrm{DPM}=$ Ductal plate malformation. EHBDO = Extrahepatic bile duct obstruction. IBD = Inflammatory bowel disease

Table 2-Clinicopathologic data for the cats of Table 1.

\begin{tabular}{|c|c|c|c|c|c|}
\hline Analyte & No. of cats & Median (range) value & $\begin{array}{c}\text { No. (\%) with results } \\
\text { above RI }\end{array}$ & $\begin{array}{c}\text { No. (\%) with results } \\
\text { below RI }\end{array}$ & $\mathbf{R I}$ \\
\hline PCV (\%) & 160 & $33(11-54)$ & $6(4)$ & $17(11)$ & $25-45$ \\
\hline$M C V(f L)$ & 128 & $45(35-62)$ & $8(6)$ & $13(10)$ & $41-51$ \\
\hline WBCs $\left(X 10^{3} / \mu \mathrm{L}\right)$ & 160 & $14.6(0.6-71.7)$ & $38(24)$ & $10(6)$ & $6.1-21.1$ \\
\hline Neutrophils (X $\left.10^{3} / \mu \mathrm{L}\right)$ & 155 & $10.9(0.5-64.4)$ & $57(37)$ & $6(4)$ & $2.6-13.6$ \\
\hline BUN $(\mathrm{mg} / \mathrm{dL})$ & 154 & $20(4-104)$ & $22(14)$ & $51(33)$ & $17-35$ \\
\hline Creatinine $(\mathrm{mg} / \mathrm{dL})$ & 147 & $1.2(0.3-2.9)$ & $6(4)$ & $2(1)$ & $0.6-2.3$ \\
\hline Glucose $(\mathrm{mg} / \mathrm{dL})$ & 152 & $127(68-891)$ & $66(43)$ & $0(0)$ & $63-140$ \\
\hline Total protein (g/dL) & 145 & $7.4(4.7-10.8)$ & $10(7)$ & $26(18)$ & $6.5-8.9$ \\
\hline Albumin $(\mathrm{g} / \mathrm{dL})$ & 152 & $3.1(1.4-4.3)$ & $0(0)$ & $76(50)$ & $3.2-4.7$ \\
\hline Globulin (g/dL) & 150 & $4.3(1.9-8.2)$ & $36(24)$ & $7(5)$ & $2.8-4.8$ \\
\hline Cholesterol (mg/dL) & 140 & $202(39-494)$ & $36(26)$ & $6(4)$ & $73-265$ \\
\hline
\end{tabular}

MCV = Mean corpuscular volume. $\mathrm{RI}=$ Reference interval. 
cal hemorrhage during surgery that abated with whole blood transfusion.

\section{Comorbidities}

Consistent with study entry criteria, all cats had histologic features consistent with S-CCHS (Figure 2). Common comorbidities included $\mathrm{EH}$ $\mathrm{BDO}$, cholelithiasis, cholecystitis, and DPM (Table 1; Supplementary Table S1), with some cats having several comorbidities enumerated in 2 or more categorical groups (eg, cats with cholelithiasis often had EHBDO). High prevalences of IBD and pancreatitis were confirmed in cats with enteric and pancreatic biopsies. Additionally, 10 cats with enteric biopsies (15\%) had IBD and alimentary small cell lymphoma. Among cats with histologically confirmed pancreatitis, 28 of 41 (68\%) had EHBDO, with 20 of these 28 (71\%) having surgically confirmed cholelithiasis.

Medications potentially increasing the risk for bacterial infection included administration (weeks to months) of glucocorticoid drugs (25/168 [15\%]) or immunomodulatory or chemotherapy drugs (eg, chlorambucil, methotrexate, cyclosporine; $n=4[2 \%]$ ) for management of skin disease, IBD, or NS-CCHS before diagnosis of S-CCHS. Conditions that may have initiated S-CCHS included dental procedures (abscessed tooth extraction, treatment for severe stomatitis or gingivitis) preceding onset of acute illness in 9 (5\%) cats, feeding of a raw chicken diet before acute illness (vomiting, diarrhea, and abdominal pain) in 1 cat, chronic bacterial and cryptococcal sinusitis associated with a retained bullet in 1 cat, and deobstipation for severe constipation completed immediately prior to illness in 1 cat. Thirty-nine (23\%) cats were diagnosed with S-CCHS before 2000, an era when testing for FIV was not readily available. In cats diagnosed with S-CCHS after 2000, 2 were FIV positive and 1 was FeLV positive.

Conditions associated with EHBDO included cholelithiasis (56/89 [63\%]), DPM (39/89 [44\%; choledochal cyst $\{19 / 39$ (49\%)\} and Caroli phenotype $\{27 / 39(69 \%)\}$, some with combined DPM phenotypes]), or narrowing of the lumen of the duodenal papilla (sphincter of Oddi). Processes limiting patency of the duodenal papilla included trauma acquired from traversing or impacted choleliths, duodenitis associated with a linear foreign body, duodenal trichobezoar compressing the duodenal papilla, ascarid ascension into the common bile duct, pancreatitis, IBD, regional neoplasia (biliary or pancreatic duct adenocarcinoma or cholangiocarcinoma), and benign intestinal polyp (causing ball-valve obstruction). Four of 68 (6\%) cats with cholecystitis developed hemobilia and bile duct occlusion by cholecystohemoliths.

Ductal plate malformations in 74 cats included $52(70 \%)$ with a Caroli phenotype (median age, 7.3 years; range, 0.5 to 20.0 years), 29 (39\%) with a choledochal cyst (median age, 7.0 years; range, 5.0 to

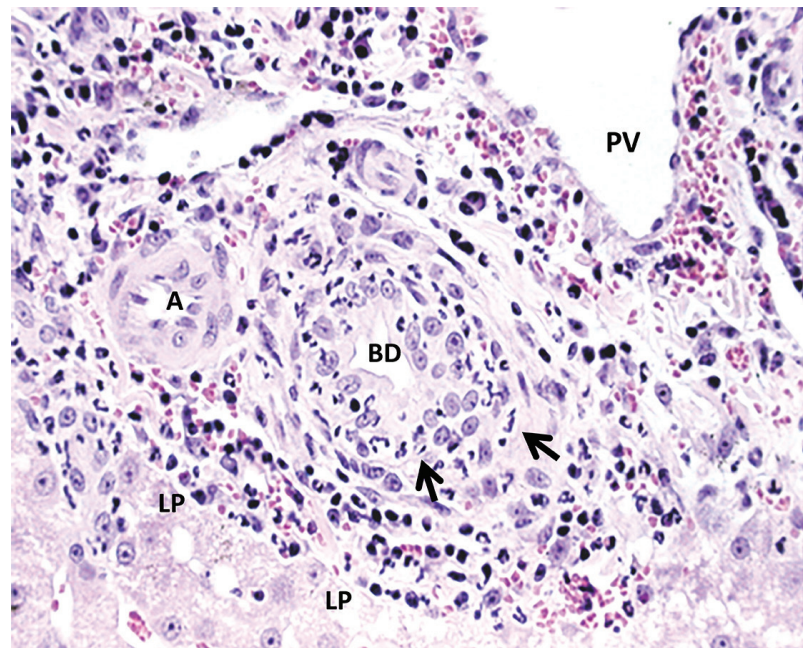

Figure 2-Representative photomicrograph of liver section (300X magnification) from a cat that has been stained with H\&E demonstrating features consistent with S-CCHS. A periductal neutrophilic infiltrate translocates across biliary epithelium (arrows) of a bile duct (BD) and breaches the limiting plate (LP) of the portal tract that defines the margin between the portal adventitial and periportal hepatic parenchyma. A portal artery (A) is unaffected, and the portal vein (PV) has perivascular congestion with RBCS.

17.0 years), and 31 (42\%) with a small proliferativelike phenotype (median age, 7.0 years; range, 0.5 to 17.0 years). Combined DPM phenotypes were documented in 35 (47\%) cats. Additionally, 5 cats had a congenital hepatic fibrosis (CHF) DPM phenotype associated with ascites and acquired portosystemic shunts, 3 had DPM-related gallbladder atresia, 3 had $\geq 1$ atretic liver lobe, and 2 had a concurrent congenital portosystemic shunt. Of 39 cats with DPM and concurrent EHBDO, 21 (54\%) had obstructive cholelithiasis. Five cats with Caroli phenotypes had mineralized microcholelithiasis detected radiographically, whereas 15 cats with Caroli phenotypes and 1 cat without DPM had intrahepatic microcholeliths detected ultrasonographically. 
Of 71 cats with cholelithiasis, 20 (28\%) had histologically confirmed pancreatitis; 4 of these also had diabetes mellitus. Sixteen cats with cholelithiasis presented for acute illness and jaundice due to sudden $\mathrm{EH}$ BDO caused by an impacted cholelith. Imaging studies (radiography or ultrasonography) detected choleliths in $58 \%$ of cats with cholelithiasis, usually involving the common bile duct, hepatic ducts, or gallbladder. Tiny amalgamations of mineralized debris $(\leq 3 \mathrm{~mm}) \mathrm{com}$ promising patency of the duodenal papilla were often overlooked by ultrasonography; these were discovered during surgical evaluation of bile duct patency. Twelve cats had choleliths only discovered at surgery, 7 detected by retrograde flushing of the common bile duct via duodenostomy. Occasionally, ultrasonographically detected choleliths that could not be confirmed at surgery completed hours to several days later. Presumably, ultrasonographically detected stones traversed the common bile duct and duodenal papilla during the lag period between imaging and surgical intervention. At surgery, these cats had palpably thickened (presumably inflamed) duodenal papillae reflecting traumatic cholelith transit. Four cats had choleliths lodged at the ampulla where the common bile duct and pancreatic duct unite, with stone impaction obstructing each ductal system. In 20 of 55 cats with suspected "idiopathic" pancreatitis, transient microcholelithic obstruction of the duodenal papilla was associated with biopsy-confirmed pancreatitis.

Stone analysis in cats revealed calcium carbonate composition in 11 of 18 (61\%); these stones were pale yellow to off-white in color; 1 cat had choleliths with a mixed calcium carbonate and calcium oxalate composition. Three cats had mixed-composition dark brown stones containing glycoproteins, cholesterol, calcium bilirubinate, and organic matrix. Four cats had choleliths containing amalgamated suppurative debris, coagulated blood, and mineral (hemocystoliths or hemocholeliths). These stones seemingly evolved from hemobilia originating in a hemorrhage-filled gallbladder. Bacterial cultures of liver, bile, or crushed choleliths from cats with analyzed stones were positive for bacteria in 10 of 17 (59\%) cats, including 9 of 11 (82\%) cats with predominant calcium carbonate composition. Bacterial cultures for 44 of $62(71 \%)$ cats with cholelithiasis were positive, with no significant difference between pigmented and nonpigmented stones in frequency of bacterial infection. In most cases, samples from crushed choleliths were combined with liver, bile, or both in an effort to optimize bacterial isolation and minimize cost. However, of 4 cats with separate cultures of liver or bile and crushed choleliths, bacteria were only isolated from crushed choleliths.

Cholecystitis (histologically diagnosed) was usually associated with historic or acute EHBDO and was typically implicated by the gross appearance of the gallbladder (hyperemia and thick wall on palpation) and occasionally by evidence of bile leakage and gallbladder rupture. Cholecystectomy in 39 cats was completed most often because of suspected cholecystitis associated with cholelithiasis and less often because of gallbladder wall necrosis or neoplasia. Of 5 cats with cholelithiasis from which stones were removed by cholecystotomy (to salvage the gallbladder), recurrent cholecystoliths developed within 18 months in 4 (80\%). Histologically, the gallbladder in cats with cholelithiasis had a distinctive thick proliferative to papilliferous mucosa thought to reflect stone-associated microtrauma (Figure 3). Cholecystoenterostomy was performed in 37 cats, of which $75 \%$ had EHBDO. Among cats undergoing cholecystoenterostomy, 16 (43\%) received a cholecystoduodenostomy and 21 (57\%) a cholecystojejunostomy. Nine cats had temporary stenting of the common bile duct to facilitate short-term bile drainage during resolution of swelling and inflammation of the duodenal papilla subsequent to surgical manipulations (ie, cannulation for flushing), cholelith- or foreign body-associated trauma, or erosive duodenitis.

\section{Bacterial infections}

Comprehensive description of bacterial culture results and immunohistochemical detection of bacteria and pathologic endotoxin exposure are provided in the companion report. ${ }^{31}$ Briefly, bacteria were cultured in 93 of 135 (69\%) cats with greater frequency of infection detected using immunohistochemical methods. ${ }^{31}$

\section{Survival time}

The prospective nature of this study allowed appraisal of patient condition and survival through continued contact with referring veterinarians and pet caregivers throughout the life of each cat. Consequently, only 6 of 168 (4\%) cases were lost to followup. Median survival time among categorical groups ranged from 240 to 694 days (Supplementary Table S1). Kaplan-Meier survival analyses confirmed significantly longer survival in cats with cholelithiasis (Gehan-Wilcoxon test, $P=0.005$; log-rank test, $P=$ 0.03 ) and cats undergoing cholecystectomy (GehanWilcoxon test, $P=0.005$; log-rank test, $P=0.005$ ) than in cats without these characteristics (Figure 4).
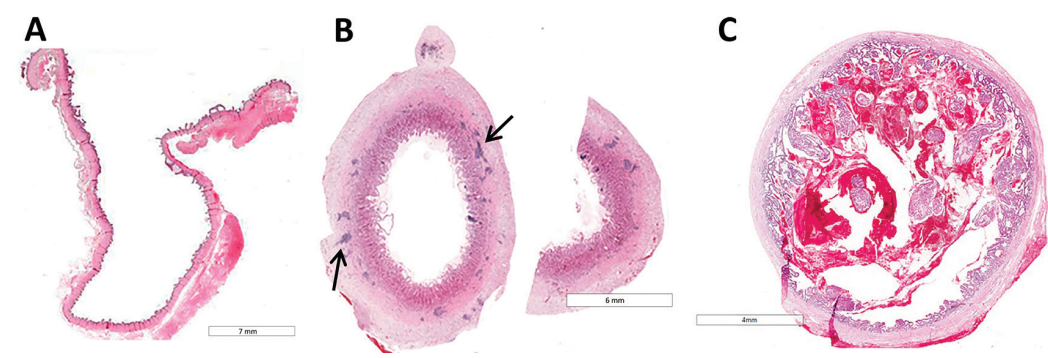

Figure 3-Photomicrographs of gallbladder sections from a cat without S-CCHS, cholecystitis, or cholelithiasis (A, bar $=7 \mathrm{~mm}$ ), and 2 cats with $\mathrm{S}-\mathrm{CCHS}$ with biliary bacterial infections associated with cholelithiasis (B, bar = $6 \mathrm{~mm} ; C$, bar $=4 \mathrm{~mm}$ ). Mural thickening and mucosal hyperplasia typically associated with cholelithiasis are illustrated in B and C. In panel $B$, lymphoid follicles (arrows) are thought to reflect chronic inflammation and/or antigenic stimulation. The cat in $\mathrm{C}$ had hemobilia, likely reflecting cholelith microtrauma. 

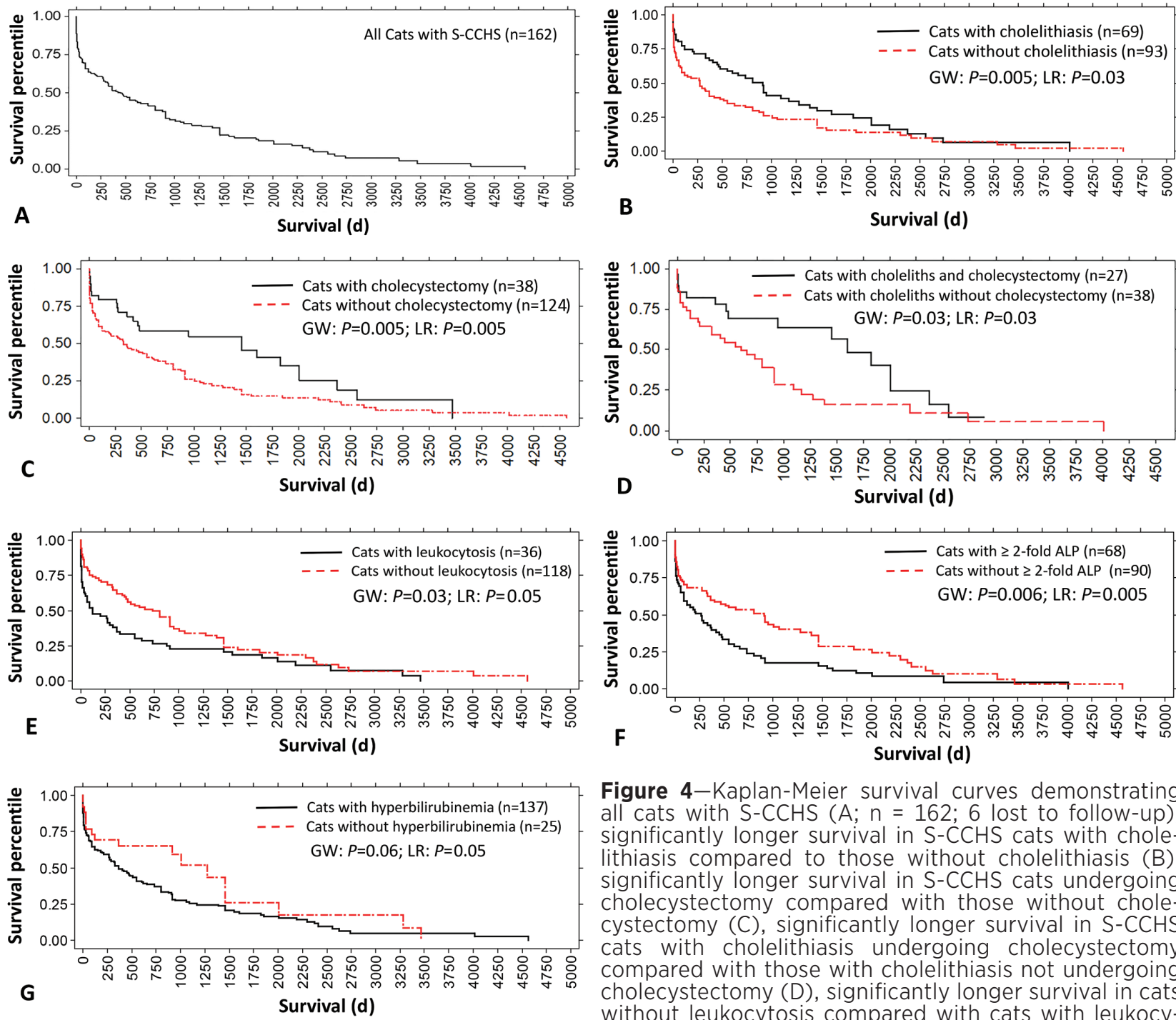

Figure 4-Kaplan-Meier survival curves demonstrating all cats with S-CCHS (A; $n=162 ; 6$ lost to follow-up), significantly longer survival in S-CCHS cats with cholelithiasis compared to those without cholelithiasis (B), significantly longer survival in S-CCHS cats undergoing cholecystectomy compared with those without cholecystectomy (C), significantly longer survival in S-CCHS cats with cholelithiasis undergoing cholecystectomy compared with those with cholelithiasis not undergoing cholecystectomy (D), significantly longer survival in cats without leukocytosis compared with cats with leukocytosis (E), significantly shorter survival in cats with a $\geq$ 2-fold increase in ALP activity compared with cats with a

Cholecystectomy in cats with cholelithiasis significantly prolonged survival relative to cats with cholelithiasis without cholecystectomy (Gehan-Wilcoxon test, $P=0.03$; log-rank test, $P=0.03$ ). Median age at death also was significantly (Gehan-Wilcoxon test, $P$ $=0.003$; log-rank test, $P=0.004$ ) older for cats with cholelithiasis than for cats without cholelithiasis. Cats with EHBDO undergoing cholecystectomy had significantly (Gehan-Wilcoxon test, $P=0.005$; logrank test, $P=0.008$ ) longer survival than cats with EHBDO without cholecystectomy. Median postoperative survival time and age at death in cats with EHBDO undergoing cholecystoenterostomy were not significantly different from values for cats without cholecystoenterostomy. There were not enough cats with temporary biliary stents to critically assess procedural impact on survival. Cats with DPM were significantly (Gehan-Wilcoxon test, $P=0.01$; log-rank test, $P=0.06$ ) younger at death, considering short-term survival data, than were cats without DPM. However, DPM was not associated with a significantly shorter survival time.

$<2$-fold increase in ALP activity (F), and significantly longer long-term survival in cats without hyperbilirubinemia compared with cats with hyperbilirubinemia $(G)$.

Among clinicopathologic parameters, leukocytosis was associated with a significant (Gehan-Wilcoxon test, $P=0.03$; log-rank test, $P=0.05$ ), negative impact on survival (Figure 4 ). Of 38 cats with leukocytosis, median survival time was 120 days (range, 1 to 3,468 days; $95 \% \mathrm{Cl}, 204$ to 714 days), whereas 122 cats lacking leukocytosis had median survival time of 394 days (range, 1 to 4,563 days; 95\% Cl, 580 to 905 days). Cats with $a \geq 2$-fold increase in serum ALP activity had a significantly shorter survival time (Gehan-Wilcoxon test, $P=0.006$; log-rank test, $P=$ 0.005 ) than did cats without $a \geq 2$-fold increase. Of 72 cats with $a \geq 2$-fold increase in ALP activity, median survival time was 193 days (range, 1 to 4,015 days; $95 \% \mathrm{Cl}, 328$ to 601 days), compared with 92 cats without $a \geq 2$-fold ALP increase that had a median survival time of 500 days (range, 1 to 4,563 
days; 95\% Cl, 609 to 994 days). Hyperbilirubinemic cats also had significantly shorter long-term survival (Gehan-Wilcoxon test, $P=0.06$; log-rank test, $P=$ $0.05)$ than did normobilirubinemic cats. Among 142 cats with a high serum total bilirubin concentration, median survival time was 274 days (range, 1 to 4,563 days; $95 \% \mathrm{Cl}, 499$ to 782 days), whereas 26 cats without a high bilirubin concentration achieved a median survival time of 785 days (range, 1 to 3,468 days; $95 \% \mathrm{Cl}, 493$ to 865 days). However, when cats were grouped by the presence or absence of jaundice or a $\geq 2$-fold increase in serum total bilirubin concentration, no significant survival difference was detected. Positive bacterial culture results had no significant survival impact; however, further details provided in the companion manuscript 31 indicated significant survival risk with some types of bacterial infection.

Eighteen cats (11 males and 7 females; median age, 8.9 years; range, 0.5 to 13.0 years) died or were euthanized within 48 hours after presentation. Of these, 3 were euthanized because of illness severity (hypotension, recumbency, or impaired cognitive responses) or diagnosis of disseminated neoplasia; 1 cat had a CHF DPM phenotype associated with abdominal effusion, acquired portosystemic shunts, and hepatic encephalopathy, and 2 cats had EHBDO caused by neoplasia (adenocarcinoma or cholangiocarcinoma). Nine cats died secondary to operative or postoperative nonresponsive hypotension, 6 with confirmed bacterial infections complicating DPM. Two cats died from dehiscence following cholecystoenterostomy, and 1 cat each died from pulmonary thromboembolism after resection of a large complex cystadenoma, septic complications associated with extracorporeal bile drainage, sepsis caused by hepatobiliary infection, and unknown causes. Of 18 cats dying within 48 hours, median duration of antecedent illness was 51 days (range, 1 to 1,125 days) and was not significantly different from the duration of antecedent illness for 150 cats with longer-term survival (median duration of antecedent illness, 30 days [range, 1 to 1,480 days]). Clinical features among cats succumbing within 48 hours included anorexia (94\%), lethargy (83\%), jaundice (72\%), weight loss (72\%), vomiting $(44 \%)$, fever $(44 \%)$ or hypothermia (33\%), abdominal effusion (38\%), hepatomegaly (33\%), anemia with a PCV < 13\% (11\%), leukocytosis (33\%), and $a \geq 2$-fold increase in serum ALT (72\%), AST (44\%), ALP (50\%), or GGT (50\%) activities. Positive bacterial culture results were obtained for 5 of 7 (71\%) cats succumbing within 48 hours. No clinical features or clinicopathologic parameters predicted the dismal prognosis in these cats relative to the longer-term survivors. Comparison of the frequency of positive culture results between cats with shorter-term survival (ie, < 48 hours) and those with longer-term survival was confounded by owner reluctance to pursue expense of bacterial culture in the face of a dismal prognosis. With this bias acknowledged, there was no significant difference between frequencies of positive culture results for cats with shorter-term survival (71\%) versus longer-term survival (69\%; 88/128 cultures). Among 6 cats with shorter-term survival and suspected idiopathic pancreatitis, 3 with enteric and pancreatic biopsies had histologically confirmed IBD and pancreatitis. Median age at death was significantly $(P=0.004)$ younger for cats dying within 48 hours (8.0 years; range, 0.5 to 17 years; $95 \% \mathrm{Cl}, 5.5$ to 10.5 years) than for cats surviving $>48$ hours (10.0 years, range, 0.5 to 20.0 years; $95 \% \mathrm{Cl}, 8.7$ to 10.3 years).

Nineteen cats experienced severe, poorly responsive hypotension during or after surgical interventions; 14 (74\%) died from this complication. This phenomenon is consistent with consequences of cholangiovenous reflux of bacteria, endotoxin, or both into the systemic circulation provoked by surgical manipulations. ${ }^{34,35}$ Comorbidities in cats succumbing to perioperative hypotension included 15 of $19(79 \%)$ cats with EHBDO, 9 of $19(47 \%)$ cats with cholelithiasis, and 9 of 19 (47\%) cats with DPM (choledochal cyst, $n=3$; Caroli, 6 ). One cat not undergoing surgical intervention suddenly developed severe hypotension refractory to IV fluid therapy subsequent to suspected sepsis following extraction of an abscessed tooth. Of 13 cats undergoing a hypotensive crisis that had bacterial cultures submitted, 10 (77\%) had positive cultures.

Twenty-seven cats with S-CCHS had concurrent or subsequently developed neoplastic conditions. Of cats with primary hepatic cancer, 5 had neoplasms associated with biliary structures (gallbladder carcinoma, $n=2$; cholangiocarcinoma, 3), 1 had a hepatic neuroendocrine carcinoma, and 1 had a hepatocellular carcinoma complicated by pathologic copper accumulation. Four additional primary biliary neoplasms developed in 2 cats with DPM and 2 cats without DPM within 3 years of S-CCHS diagnosis (each had a cholangiocarcinoma). Metastatic carcinoma of undetermined origin was diagnosed at surgery in 1 cat and within 9 months of S-CCHS diagnosis in 2 other cats. Additionally, 10 cats had alimentary lymphoma; 6 were diagnosed concurrently with S-CCHS and 4 were diagnosed 3 to 6 months later; 3 of these cats also had Caroli DPM. Other neoplastic disorders in 3 cats developing within 1.5 years after diagnosis of S-CCHS included myelogenous leukemia, enteric hemangiosarcoma, and an invasive subglossal tumor. Among 22 cats with death related to neoplasia, 11 (50\%) had primary hepatic cancer.

Cause of death in 134 cats with S-CCHS was attributed to liver disease in 111 (83\%). We were unable to evaluate survival status in cats classified using a previously proposed histologic scheme defining acute and chronic stages of feline S-CCHS because intraindividual variation of histologic changes defied such categorization. ${ }^{5}$ Thus, the clinical utility of this categorization scheme in directing treatment or predicting survival time could not be appraised.

\section{Treatments}

Most cats surviving to hospital discharge received long-term (> 1 to 6 months) antimicrobial administration tailored to cultured bacteria or empirically in response to vacillating liver enzyme activity, fever, or leukocytosis. Antimicrobials also were administered IV intraoperatively after collection of 
culture inoculates (imipenem or second-generation cephalosporin commonly administered). Many cats received $N$-acetylcysteine during initial hospitalization (induction dose of $140 \mathrm{mg} / \mathrm{kg}$, IV, over $20 \mathrm{~min}$ utes, followed by $70 \mathrm{mg} / \mathrm{kg}$, IV, over 20 minutes) for presurgical antioxidant protection. Most cats also were prescribed long-term but variable courses of ursodeoxycholic acid and S-adenosylmethionine (SAMe) for choleretic, cytoprotective, antioxidant, and metabolic effects. Ursodeoxycholic acid was administered at 10 to $15 \mathrm{mg} / \mathrm{kg}$, PO, every 12 to 24 hours with food to increase bioavailability and was often combined with taurine (250 mg, PO, q 24 h) in consideration of the obligatory taurine conjugation of bile acids in cats and the potential risk for acutely acquired taurine insufficiency in cats with chronic or cyclic hyporexia. Enteric-coated SAMe was administered at 40 to $60 \mathrm{mg} / \mathrm{kg}$, PO, every 24 hours on an empty stomach to optimize SAMe bioavailability, to achieve a glutathione-mediated choleresis and antioxidant benefits. A lower SAMe dose $(20 \mathrm{mg} / \mathrm{kg}$, q $24 \mathrm{~h}$ ) was often used chronically for its metabolic and antioxidant effects. Supplemental water-soluble $B$ vitamins were administered in IV fluids during hospitalization. Vitamin $\mathrm{B}_{12}$ supplementation (250 $\mathrm{\mu g}$, SC or IM) was initially provided for many cats, with the need for chronic supplementation thereafter determined by sequential weekly to monthly assessments of $B_{12}$ concentrations. Water-soluble vitamin E (10 U/kg, PO with food, q 24 h) was given for antioxidant protection in cats with EHBDO. Vitamin $\mathrm{K}_{1}$ was parenterally administered to all but 2 jaundiced cats at a dose of 0.5 to $1.5 \mathrm{mg} / \mathrm{kg}$, SC or IM, every 12 hours for 3 doses before invasive procedures. No specific diets were prescribed except for cats with $\mathrm{IBD}$ requiring an antigen-modified formulation.

\section{Discussion}

The clinical features of feline S-CCHS detailed herein complement and expand previous descriptions in the veterinary literature. ${ }^{6-30}$ Feline S-CCHS has a diverse spectrum of clinical features variably including fever or hypothermia; nonresponsive hypotensive recumbency; chronic episodic illness associated with lethargy, hyporexia, and vomiting; vacillating liver enzyme activities; jaundice; and vague signs of illness. Despite isolation of bacteria in $69 \%$ of cats with submitted cultures, fewer than $50 \%$ of cats were febrile. Clinicopathologic features of feline S-CCHS overlap with other feline cholestatic disorders, making liver biopsy a prerequisite for definitive diagnosis. Hematologic abnormalities were uncommon, with $<25 \%$ of cats demonstrating left-shifted neutrophilic leukocytosis. The absence of a hematologic response to infection in many cats likely reflected compartmentalization of inflammation or infection to hepatobiliary tissues. Leukocytosis functioned as a negative survival metric, presumably reflecting systemic endotoxemia or sepsis. Despite $\geq 2$-fold increase in serum total bilirubin concentration in $80 \%$ of cats, only $67 \%$ became clinically jaundiced; neither hyperbilirubinemia nor jaundice had clinical value as survival metrics. Likewise, despite common increases in liver enzyme activities, predominated by ALT, only ALP functioned as a discriminating survival metric. Cats with $a \geq 2$-fold increase in serum ALP activity had a significantly shorter survival time, compared with cats without this feature. As previously reported, the fold increase in GGT activity often superseded increases in ALP activity (Figure 1), presumably reflecting injury to hepatic and pancreatic ductal elements. ${ }^{36}$ Critically prolonged PT and APTT in cats with obstructive cholangiopathy ( $\geq 7$-day duration) likely reflected the impaired enterohepatic circulation of bile acids that restricted alimentary uptake of lipophilic vitamin $\mathrm{K}_{1} .{ }^{37}$ This hypothesis was validated in 6 cats in which coagulation test results normalized after parenteral vitamin $\mathrm{K}_{1}$ treatment. Hemorrhagic crises were uncommon among cats in the studied population because most had been prophylactically treated with parenteral vitamin $\mathrm{K}_{1}$ as a standard of care. We used this intervention because neither PT nor aPTT is reliably sensitive for predicting vulnerability to vitamin $\mathrm{K}_{1}$ responsive coagulopathy in cats with liver disease. ${ }^{37}$ We encountered no adverse events associated with $\mathrm{SC}$ or IM vitamin $\mathrm{K}_{1}$ administration but caution that IV administration should be avoided because of risk for anaphylactoid reaction. ${ }^{38-40}$

Among cats with S-CCHS undergoing enteric or pancreatic biopsies, we confirmed IBD in $88 \%$ and pancreatitis in 93\%. These are higher frequencies than previously reported for a small necropsybased study 6 of feline S-CCHS that reported $44 \%$ and $58 \%$ frequencies of IBD and pancreatitis, respectively. However, that study represented a population survey, whereas purposeful subset sampling was performed in the present study. A similar necropsy-based population survey of feline CCHS predominantly involving cats with NS-CCHS revealed an 83\% frequency of IBD and $50 \%$ frequency of pancreatitis (50\%). ${ }^{41}$ The relevance of IBD to feline S-CCHS is that it amplifies risk for enteric bacterial and endotoxin translocation secondary to altered bowel vascular and lymphatic integrity, as well as development of enteric dysbiosis. ${ }^{42-46}$ Regional duodenal inflammation also increases the risk for bacterial ascension across the duodenal papilla, infecting biliary and pancreatic ductal elements. ${ }^{12,42-47}$ A cohort of cats in the present study had alimentary lymphoma that similarly should increase the risk for enteric bacterial translocation. Pancreatitis with feline S-CCHS in the present study was commonly associated with distal EHBDO and cholelithiasis, disorders provoking ascension of bile and bile-borne bacteria into the common bile and pancreatic ducts via the feline anatomic union of these structures. ${ }^{48}$

Among comorbidities associated with feline S-CCHS in the present study, EHBDO predominated, frequently complicating other conditions. Numerous factors imposed by EHBDO increase enteric bacterial translocation and bacterial dissemination. Reduced bile acid and biliary IgA access to the alimentary canal is permissive to development of enteric dysbiosis as well as enteric translocation of bacteria and endotoxin. 45-47,49-54 Additionally, EHBDO disrupts tight junctions in hepatocyte membranes that normally 
segregate canalicular bile from sinusoidal perfusates, reduces Kupffer cell bacterial phagocytosis, and leads to development of leaky capillary fenestrations in the peribiliary arterial plexus. ${ }^{43,45,47,55-58}$ Ultimately, bacteria from contaminated portal tracts and sinusoids disseminate to regional lymphatics (portal, sinusoidal ultralymph) with subsequent drainage into the thoracic duct and then into the systemic circulation. These detrimental changes contribute to the phenomenon of cholangiovenous reflux, a pathologic process whereby bacteria and their products regurgitate from bile into lymphatics and hepatic sinusoids, leading to acute systemic bacteremia and endotoxemia. This manifests as weakness, collapse, and nonresponsive hypotension and can progress to acute renal failure and death. ${ }^{34,35,59} \mathrm{We}$ and others have observed this phenomenon in cats with obstructive cholestasis despite pre- and perioperative antimicrobial administration, normalized hydration and electrolyte status, cautious anesthetic protocols, and expert surgical skills. ${ }^{11,19,34}$

Additional factors contributing to bile-borne bacterial infection include changes impacting function or structure of the sphincter of Oddi, common to several comorbidities identified in this study (eg, IBD, cholelithiasis, and causes of regional duodenitis). In health, the feline biliary tract is typically sterile, despite the normal flux of bacteria from the splanchnic circulation, although the sphincter of Oddi may harbor surface bacteria. ${ }^{44}$ This functional barrier normally prevents retrograde invasion of enteric flora into the biliary tree.44,58,60-62 Another vulnerability associated with S$\mathrm{CCHS}$ is development of biliary mucosal irregularities (ie, DPM, bile duct or gallbladder neoplasia, or gallbladder mucosal hyperplasia secondary to cholelithiasis), or niches within the irregular surface of choleliths. Surface irregularities avail adherence niches for bacterial biofilm accretion or accumulation of small static bile pools ideal for in situ bacterial replication. ${ }^{18,61}$ We documented a high prevalence of bacterial infection in cats with cholelithiasis, similar to the relationship recognized in humans. ${ }^{31}$ We found no male predilection for feline cholelithiasis, as previously suggested. ${ }^{13}$ It is clear that choleliths can lead to EHBDO and that chronic EHBDO does not cause cholelith formation simply as a consequence of bile flow stasis. 63,64 However, what is not clear is whether choleliths cause or reflect biliary tree infection or disease. ${ }^{61}$ Cats with choleliths generally remain free of clinical signs until stones obstruct the gallbladder or common bile duct. ${ }^{65-74}$ In humans, brown-pigment stones form secondary to septic inflammation and are composed of organic matrix amalgamated with bilirubinate, mineral concretions, and bacterial microcolonies (biofilm). ${ }^{62,69,75-79}$ The brown color reflects bacterial deconjugation of bilirubin glucuronide to water insoluble bilirubinate.69,74-77 Other bacteria (eg, Escherichia coli) can additionally produce phospholipases that hydrolyze fatty acids, saponifying calcium to cholelithic concretions. ${ }^{76}$ Choleliths forming secondary to cholecystitis or gallbladder dysmotility seemingly nucleate in clefts within proliferative or irregular gallbladder mucosa. Consistent with this lithogenic process, we often observed mineralized micro- choleliths nestled against or within proliferative gallbladder mucosa in cats with cholecystitis and cholelithiasis. Microcholeliths also occasionally affiliated with biliary epithelium in stagnant bile pools within sacculated malformed bile ducts of cats with Caroli DPM. 31,32 We consistently observed proliferative gallbladder mucosa in cats with cholecystic cholelithiasis (Figure 3), similar to the mucosal proliferation recognized in humans with chronic cholelithiasis. This morphologic feature is considered to reflect cholelith-imposed traumatic mucosal irritation. ${ }^{78,80}$ Reactive lymphoid follicles, occasionally observed in gallbladder sections, likely reflected response to chronic inflammation and bacterial infection. ${ }^{79}$

Of analyzed choleliths, pale white stones of calcium carbonate composition predominated. These were radiodense, often large enough ( $>3 \mathrm{~mm}$ in diameter) for radiographic detection and often but not always detected ultrasonographically. Pigmented choleliths (ie, brown choleliths with variable mixed composition and black choleliths representing conglomerated blood and inflammatory debris) were typically radiolucent but were often detected by ultrasonography. Since 1955, publications have characterized choleliths from 32 cats; of 17 analyzed stones, 7 were predominantly calcium carbonate; 7 were mixed calcium bilirubinate, calcium carbonate, and cholesterol; and 3 had black bilirubin or hemoglobin composition (including 2 Somali cats with pyruvate kinase deficiency causing chronic hemolysis). $8,13,14,18-21,23-29,72-74$ In this and former reports, white and brown pigment stones are associated with bacterial infection. Therefore, describing pigment stones as infection stones, as noted in human beings, is inappropriate in cats. Prior reports $8,13,20,26,27,29,73,74$ describe bacterial isolation from bile, liver, or choleliths in approximately $71 \%$ of cats with cholelithiasis, similar to findings reported herein. As documented in humans, we also demonstrated bacteria harbored within the crystalline structure or laminating layers of choleliths. $31,80,81$ This finding corroborates our observation that inoculates from crushed choleliths increased bacterial detection in feline S-CCHS. 31,80,81 Indeed, in some cats with separate bacterial cultures of liver or bile and choleliths, only crushed choleliths yielded bacterial isolates. ${ }^{31}$ Considering that crushed choleliths were inconsistently submitted for bacterial culture in the present study, it is likely that cholelithrelated infection was overlooked in some cats. The close association between bacterial infection and cholelithiasis in cats with S-CCHS has therapeutic implications. As some choleliths are impermeable to antimicrobial penetration, biliary infection may persist in cats with residual cholelithiasis. ${ }^{75-77}$ Based on observations made in the present study, an informed standard of care for cats with symptomatic cholelithiasis should include cholelith removal, cholecystectomy (unless the gallbladder is needed for cholecystoenterostomy), and flushing of the common bile duct to ensure patency. Considering our findings, including the unique papilliferous gallbladder mucosal hyperplasia associated with cholelithiasis, the location of choleliths in cats with EHBDO, and the 
clinical response to cholecystectomy, we conclude that the gallbladder is the most likely site of cholelith nucleation in cats. This conclusion is supported by the Kaplan-Meier survival analyses documenting a survival benefit for cholecystectomy in feline cholelithiasis. The survival benefit of cholecystectomy was underscored by our documentation of recurrent cholelithiasis within 18 months in 4 of 5 cats with choleliths removed by cholecystotomy rather than cholecystectomy. As inspection and flushing of the common bile duct is needed to ensure patency of the extrahepatic biliary tree in cats with cholelithiasis, minimally invasive cholecystectomy for cats with clinical cholelithiasis is ill advised, as it does not adequately address ductal patency. Elimination or control of bacterial infection in cats with cholecystitis and S-CCHS associated with DPM remains problematic because of the high risk for widespread intrahepatic cholelithiasis in DPM that defies surgical remediation. ${ }^{32}$

Choleliths associated with vacillating liver enzyme activities, fluctuating hyperbilirubinemia, and episodic clinical signs (vomiting, inappetence, lethargy, and vague illness) or sudden-onset EHBDO should be classified as symptomatic (ie, clinical) and warrant surgical intervention. Common use of abdominal ultrasonography has increased the recognition of asymptomatic (ie, subclinical) cholelithiasis in cats. Previously, recommendations for subclinical cholelithiasis consisted of a watch, wait, and retest strategy. However, the high prevalence of bacterial infection in feline cholelithiasis, confirmed in the present study, prompts reconsideration of these managerial and surveillance practices. ${ }^{31}$ Finding subclinical cholelithiasis should heighten owner vigilance for clinical signs that may have previously been overlooked and consideration of antimicrobial administration. Furthermore, based on the authors' extensive experience with this syndrome, periodic assessment of serum liver enzyme activities, serum total bilirubin concentration, and ultrasonography (for localization and dimensional measurement of choleliths) can guide the propriety of surgical intervention.

A previously unrecognized complication of feline cholelithiasis revealed in the present study is microcholelith-associated "idiopathic" pancreatitis, similar to a syndrome documented in humans. ${ }^{82-86}$ This condition is associated with meal-related abdominal pain and microcholelith (ie, a cholelith $\leq 3$ $\mathrm{mm}$ in diameter) impaction of the sphincter of Oddi. Consequential inflammation and swelling of the duodenal papilla impose stenosis or spasm that can limit bile flow or potentiate sphincter incontinence after stones transit this orifice. ${ }^{82-86}$ Reflux of bile or mixed biliary-pancreatic secretions into the pancreatic ductal system consequent to intermittent obstruction can provoke pancreatitis. ${ }^{82}$ In such patients, fluctuating signs of illness and clinicopathologic markers suggestive of pancreatitis may dominate the clinical scenario, diverting attention from the underlying cause. As in humans, we confirm relative insensitivity of routine ultrasonography for detection of microcholelith-associated pancreatitis, likely due to factors restricting the imaging window (ie, regional ileus, overlying bowel gas, and patient discomfort). $82,83,85,86$ Our contention that microcholelith-associated "idiopathic" pancreatitis exists in cats is supported by concurrent documentation of interstitial pancreatitis or pancreatic periductal inflammation in 20 cats with cholelithiasis as well as the confirmation of transiting choleliths in 28 of 55 cats with clinically suspected "idiopathic" pancreatitis (sequential ultrasonography or gross observations in surgery). Indeed, a subset of cats with suspected microcholelith-associated "idiopathic" pancreatitis only had cholelithic debris identified during surgical flushing of the duodenal papilla. We provide proof of principle for microcholelith-associated "idiopathic" pancreatitis in cats where cyclic illness and clinicopathologic features implicating pancreatic inflammation or injury were remediated by cholelith removal, cholecystectomy, flushing of the extrahepatic bile duct to patency, and long-term treatment with ursodeoxycholic acid. Thus, we propose that cats with illness attributed to "idiopathic" pancreatitis be carefully scrutinized for transiting microcholeliths.

At the onset of the present study 40 years ago, we did not anticipate finding an association between biliary malformations and S-CCHS. However, we herein affirm DPM as a frequent comorbidity of feline S-CCHS. Ductal plate malformations are congenital syndromes reflecting mutations impacting function or structure of primary cilia. ${ }^{87-95}$ Defective structure or function of these organelles impacts embryonic tubulogenesis, including formation of biliary and pancreatic ductal structures and renal tubules. ${ }^{88-91}$ Initial differentiation of the portal tract involves formation of an embryonic "ductal plate" composed of a double layer of primordial epithelium surrounding a developing portal vein. ${ }^{87,91}$ This structure matures through apoptotic remodeling and cell proliferation, orchestrated by complex interactions of numerous genes and signaling molecules. ${ }^{32,89,91-95}$ The diversity of involved genes and complexity of signaling interactions explain the wide phenotypic spectrum among DPM syndromes. ${ }^{32,87,89-95}$ Insufficient involution of ductal elements at the level of interlobular and intralobular bile ducts results in the formation of either large irregular saccular dilated ductal elements (Caroli DPM phenotype) or enumerable small, tightly formed proliferative-like bile ducts (small proliferative-like DPM phenotype; these cholangiocytes are not proliferative but resemble proliferative cells). When either phenotype is associated with exuberant portal fibrosis forming portal-to-portal bridging fibroductal partitions that impose presinusoidal portal hypertension, a CHF phenotype evolves, causing splanchnic portal hypertension, abdominal effusion, and acquired portosystemic shunting. ${ }^{92-94}$ A CHF DPM phenotype was observed in 5 cats of the present study. Because chronic progressive fibrogenesis in DPM with aging can lead to the eventual manifestation of CHF, this phenotype may not be evident at the time of liver biopsy but may evolve over ensuing years. ${ }^{32}$ Choledochal cyst DPMs are a malformative appendix-like outpouching or diverticulum projecting from the common bile duct (at 
any level). Histologic criteria for diagnosis of DPM are provided elsewhere. ${ }^{32,96}$

Among DPM morphologies in cats with S-CCHS, the Caroli phenotype was most common (70\%), with fewer small proliferative-like (42\%) and choledochal cyst (39\%) phenotypes. However, numerous cats displayed combined DPM phenotypes. Although DPM imposes risk for chronic bile-borne bacterial infection, Caroli and choledochal cyst phenotypes demonstrated the highest risk for cholelithiasis and EHBDO. The expected etiopathogenic scenario involves the chronic pooling of bile in Caroli malformed (sacculated and irregular) bile ducts that amplify risk for bacterial biofilm accumulation and cholelith nucleation. Choledochal cysts were most often located at the level of the duodenal papillae. In this location, these cystic malformations seemingly provoked incompetence or occlusion of the sphincter of Oddi, leading to subsequent bacterobilia. We also observed that choledochal cysts may house an exclusive bacterial infection. In cats of this study, development of bile duct obstruction either from choledochal cyst expansion or accumulation of microcholelith debris at the level of the duodenal papilla led to a need for surgical intervention. Because DPM phenotypes have only recently been defined in domestic animals, they are not uniformly recognized by veterinary pathologists. ${ }^{32}$ Common erroneous classifications included chronic cholangitis, chronic EHBDO, and biliary cirrhosis. Most cats with DPM are not initially hyperbilirubinemic and have normal or only mildly increased serum liver enzyme activities. Clinicopathologic abnormalities emerge when DPM is complicated by S-CCHS, NS-CCHS, cholelithiasis, or EHBDO. We occasionally recognized additional congenital malformations in cats with DPM, as previously described in dogs with DPM, including concurrent congenital portosystemic shunts, gallbladder atresia, and severe hypoplasia of 1 or more liver lobes. ${ }^{32}$ It is acknowledged that DPM in humans and dogs imposes a lifelong risk for bacterial infection and cholelithiasis. 32,90,93-95 Given findings of the present study, cats with DPM have similar risks. Management of DPM complicated by S-CCHS in cats thus requires long-term (lifelong) antimicrobial administration, optimally tailored to cultured bacteria. Treatment of choledochal cysts also requires permanent decompression by cyst resection, marsupialization, or enteric anastomosis. Management of DPM complicated by cholelithiasis requires removal of choleliths from the extrahepatic biliary tree and cholecystectomy; even an atretic gallbladder can function as an infection sump and should be removed. In addition to antimicrobials, Caroli DPM should be managed with choleretic agents. However, small proliferativelike DPM may not benefit from choleretics, as the enumerable bile duct profiles may not contiguously interconnect with a functional biliary tree.

Because of the prospective design of the present long-term study, we achieved definitive follow-up in $96 \%$ of cases. Median survival time among categorical groups varied widely (240 to 694 days). Cats dying or euthanized within 48 hours of presentation were more likely to be physically frail (hypotensive, severely lethargic, and recumbent) or have evidence of disseminated neoplasia than were other cats. Otherwise, these cats had no distinguishing clinical or clinicopathologic features that predicted a dismal prognosis. Although we demonstrated a significant negative survival impact of leukocytosis, $\geq 2$-fold increase in serum ALP activity, and hyperbilirubinemia, these clinicopathologic metrics have no clinical utility in predicting poor prognosis for individual cats. Categorizing cats on the presence or absence of jaundice or $\geq 2$-fold increase in total bilirubin concentration failed to demonstrate significant survival impact. Cats with DPM were significantly younger at diagnosis and death than were cats without DPM, reflecting the congenital nature of this comorbidity and its association with bacterial cholangitis, cholelithiasis, EHBDO, and other occasional malformations. Cats with cholelithiasis and cats with illnesses managed or cured by cholecystectomy had significantly longer survival times and older ages at death than did cats with other comorbidities. These findings underscore the propriety of cholecystectomy as a standard of care for cholelithiasis and cholecystitis (unless biliary enteric anastomosis is needed for biliary bypass) in cats. Cholecystoenterostomy had no negative survival impact among cats with EHBDO, despite clinical concerns regarding postoperative chronic bile-borne infection. It is unfortunate that there were too few cats with temporary biliary stenting to evaluate its survival impact relative to cholecystoenterostomy. During the time span of this study, temporary biliary stenting was considered a short-term palliative solution for cats with poor long-term prognosis and was rarely used.

General treatment for cats with suspected S-CCHS should initially include broad-spectrum antimicrobial coverage subsequently tailored to cultured bacteria. Despite common presurgical antimicrobial administration, we still encountered cholangiovenous reflux in some cats and were able to isolate bacteria in 69\% of submitted cultures. Our relatively high rate of culture positivity compared with previous studies in cats likely reflects our common practice of using combined culture inoculates. Considering that we showed a greater number of bacterial infections in our companion report ${ }^{31}$ through combined interpretation of culture and immunohistochemical methodologies for pathogen detection, we suspect that antimicrobials did suppress the ability to culture some bacteria. Nevertheless, we recommend that broad-spectrum antimicrobials be administered presurgically and continued in cats with suspected S-CCHS until results of liver and gallbladder biopsies and cultures are known and clinical response is appraised.

Antioxidant supplementation is also recommended for cats with S-CCHS because of associated bacterial infection, suppurative inflammation, and cholestasis that each impose oxidative injury. 31,97 We recommend initial IV administration of $\mathrm{N}$-acetylcysteine as a direct free radical scavenger and provider of cysteine (the limiting essential feline amino acid for glutathione synthesis) in hospitalized cats. ${ }^{97}$ 
We also recommend administration of bioavailable SAMe when oral medications are possible because of the essential role of SAMe as an intermediary metabolite for a multitude of metabolic pathways (eg, vitamin $B_{12}$ activation, methylation reactions, and generation of thiol-containing antioxidants [glutathione and thioredoxin] as well as glutathione-mediated choleresis). ${ }^{98,99}$ Cats jaundiced for more than several days should be supplemented with oral water-soluble vitamin $\mathrm{E}$ and parenteral (SC or IM) vitamin $\mathrm{K}_{1}$ administration because of the potential for mechanical cholestasis prohibiting enteric assimilation of fatsoluble vitamins, based on studies in children with biliary atresia. ${ }^{100,101}$ Because vitamin E scavenges radicals propagating lipid membrane peroxidation, deficiency of vitamin $E$ may potentiate diseaserelated oxidative injury and fibrogenesis. ${ }^{102}$ However, excessive dosing of vitamin $\mathrm{E}$ must be avoided, as it can lead to accumulation of injurious tocopheroxy radicals and also interfere with carboxylation of vitamin K-dependent coagulation factors. ${ }^{103-105}$ Coagulation-related complications of vitamin $\mathrm{E}$ administration are especially relevant in the circumstance of low vitamin $\mathrm{K}_{1}$ that may evolve with EHBDO. ${ }^{105}$ Cats with chronic jaundice requiring urgent surgical intervention may need plasma transfusion to ensure adequate coagulation factors.

Combinations of bile acid-dependent and bile acid-independent choleretics were recommended for most cats in the present study once EHBDO was decompressed. Bile acid-dependent choleresis was augmented with ursodeoxycholic acid, whereas highdose bioavailable SAMe was used to augment bile acid-independent glutathione-mediated choleresis. ${ }^{97}$ However, initiating ursodeoxycholic acid before decompression of mechanical cholestasis can accelerate liver injury and fibrosis. ${ }^{106,107}$ When long-term ursodeoxycholic acid administration was prescribed, it was often supplemented with taurine in cats with a finicky appetite because all bile acids are obligatorily conjugated with this essential feline amino acid. In addition to the choleretic benefit, ursodeoxycholic acid protects biliary and hepatocyte membranes against injurious hydrophobic bile acids known to accumulate in cholestatic hepatopathies. ${ }^{107-109}$ In cholangiocytes, ursodeoxycholic acid upregulates secretinmediated bicarbonate production known to protect ductular epithelium. ${ }^{108}$ Additional cytoprotective effects include stabilization of hepatocyte membranes and enhanced defense against oxidative stress (ie, upregulation of glutathione, SAMe, and thioredoxin synthesis). ${ }^{107,109-114}$ Antioxidant effects are valuable in cholestasis where overproduction of mitochondrial peroxide and formation of oxidative hydroxynonenal protein adducts damage cellular structure and enzymes.107,109-117 Of additional benefit, ursodeoxycholic acid has been shown to enhance biliary and Kupffer cell endotoxin elimination and to reduce cholangiocyte endotoxin accumulation. ${ }^{118}$

In conclusion, the present study elucidated common clinical and clinicopathologic features of feline $\mathrm{S}-\mathrm{CCHS}$, including its association with bacterial infection and common comorbidities that increase the risk for bile-borne bacterial infection. Common comorbidities included EHBDO, DPM, cholelithiasis, cholecystitis, IBD, and pancreatitis. We identified for the first time that DPM is an important coexistent condition with S-CCHS and that cats with DPM have significantly shorter life spans than cats with other $\mathrm{S}-\mathrm{CCHS}$ comorbidities. Our findings also documented microcholelithiasis masquerading as a syndrome of "idiopathic" feline pancreatitis. Survival analyses substantiated that cholelithiasis and disorders resolvable by cholecystectomy have significantly better prognoses than S-CCHS associated with other comorbidities. Findings also confirmed that histologic subclassification of feline S-CCHS into acute and chronic stages lacks practical utility because of wide variability in histologic lesions among liver lobes in the same cat.

\section{Acknowledgments}

Funded in part by the Winn Feline Foundation.

The authors declare that there were no conflicts of interest.

\section{References}

1. Nakanuma Y, Zen Y, Portmann BC. Diseases of the bile duct. In: Burt AD, Portman BC, Ferrell LD, eds. MacSween's Pathology of the Liver. 6th ed. Churchill Livingstone; 2007:491-562.

2. Day MJ. Immunohistochemical characterization of the lesions of feline progressive lymphocytic cholangitis/ cholangiohepatitis. J Comp Pathol. 1998;119(2):135147.

3. Warren A, Center S, McDonough S, et al. Histopathologic features, immunophenotyping, clonality, and eubacterial fluorescence in situ hybridization in cats with Iymphocytic cholangitis/cholangiohepatitis. Vet Pathol. 2011;48(3):627-641.

4. Fickert P, Fuchsbichler A, Wagner M, et al. Regurgitation of bile acids from leaky bile ducts causes sclerosing cholangitis in mdr2 (abcb4) knockout mice. Gastroentero/ogy. 2004;127(1):261-274.

5. Van den Ingh TSGAM, Cullen JM, Twedt DC, et al. Morphological classification of biliary disorders of canine and feline liver. In: Rothuizen J, Bunch SE, Charles JA, et al, eds. WSAVA Standards for Clinical and Histological Diagnosis of Canine and Feline Liver Disease. Saunders Elsevier; 2006:61-76.

6. Callahan Clark JE, Haddad JL, Brown DC, Morgan MJ, Van Winkle TJ, Rondeau MP. Feline cholangitis: a necropsy study of 44 cats (1986-2008). J Feline Med Surg. 2011;13(8):570-576.

7. Twedt DC, Cullen J, McCord K, Janeczko S, Dudak J, Simpson $\mathrm{K}$. Evaluation of fluorescence in situ hybridization for detection of bacteria in feline inflammatory liver disease. J Feline Med Surg. 2014;16(2):109-117.

8. Hirsch VM, Doige CE. Suppurative cholangitis in cats. J Am Vet Med Assoc. 1983;182(11):1223-1226.

9. Jackson MW, Panciera DL, Hartman F. Administration of vancomycin for treatment of ascending bacterial cholangiohepatitis in a cat. J Am Vet Med Assoc. 1994;204(4):602-605

10. Shaker EH, Zawie DA, Garvey MS, Gilbertson SR. Suppurative cholangiohepatitis in a cat. J Am Anim Hosp Assoc. 1991;27(2):148-150.

11. Buote NJ, Mitchell SL, Penninck D, Freeman LM, Webster CRL. Cholecystoenterostomy for treatment of extrahepatic biliary tract obstruction in cats: 22 cases (1994-2003). J Am Vet Med Assoc. 2006;228(9):1376-1382. 
12. Zawie DA, Garvey MS. Feline hepatic disease. Vet Clin North Am Small Anim Pract. 1984;14(6):1201-1230.

13. Eich CS, Ludwig LL. The surgical treatment of cholelithiasis in cats: a study of nine cases. J Am Anim Hosp Assoc. 2002;38(3):290-296.

14. Morrison WB. Cholangitis, choledocholithiasis, and icterus in a cat. Vet Pathol. 1985;22(3):285-286.

15. Gagne JM, Armstrong PJ, Weiss DJ, Lund EM, Feeney DA, King VL. Clinical features of inflammatory liver disease in cats: 41 cases (1983-1993). J Am Vet Med Assoc. 1999;214(4):513-516.

16. Lapointe JM, Higgins R, Barrette N, Milette S. Enterococcus hirae enteropathy with ascending cholangitis and pancreatitis in a kitten. Vet Pathol. 2000;37(3):282-284.

17. Brain PH, Barrs VR, Martin P, Baral R, White JD, Beatty JA. Feline cholecystitis and acute neutrophilic cholangitis: clinical findings, bacterial isolates and response to treatment in six cases. J Feline Med Surg. 2006;8(2):91-103.

18. Mayhew PD, Weisse CW. Treatment of pancreatitisassociated extrahepatic biliary tract obstruction by choledochal stenting in seven cats. J Small Anim Pract. 2008;49(3):133-138.

19. Mayhew PD, Holt DE, McLear RC, Washabau RJ. Pathogenesis and outcome of extrahepatic biliary obstruction in cats. J Small Anim Pract. 2002;43(6):247-253.

20. Baker SG, Mayhew PD, Mehler SJ. Choledochotomy and primary repair of extrahepatic biliary duct rupture in seven dogs and two cats. J Small Anim Pract. 2011;52(1):32-37.

21. Bacon NJ, White RAS. Extrahepatic biliary tract surgery in the cat. A case series and review. J Small Anim Pract. 2003;44(5):231-235.

22. Pressel MA, Fox LE, Apley MD, Simutis FJ. Vancomycin for multi-drug resistant Enterococcus faecium cholangiohepatitis in a cat. J Feline Med Surg. 2005;7(5):317-321.

23. Gibson KS. Cholelithiasis and choledocholithiasis in a cat. J Am Vet Med Assoc. 1952;121(907):288-290.

24. Wigderson FJ. Cholelithiasis in a cat. J Am Vet Med Assoc. 1955;126(937):287.

25. O'Brien TR, Mitchum GD. Cholelithiasis in a cat. J Am Vet Med Assoc. 1970;156(8):1015-1017.

26. Naus MJ, Jones BR. Cholelithiasis and choledocholithiasis in a cat. N Z Vet J. 1978;26(6):160-161.

27. Wolf AM. Obstructive jaundice in a cat resulting from choledocholithiasis. J Am Vet Med Assoc. 1984;185(1):85-87.

28. Heidner GL, Campbell KL. Cholelithiasis in a cat. J Am Vet Med Assoc. 1985;186(2);176-177.

29. Jorgensen LS, Pentlarge VW, Flanders JA, Harvey HJ. Recurrent cholelithiasis in a cat. Compend Contin Educ Pract Vet 1987;9:265-270.

30. Morrison S, Prostredny J, Roa D. Retrospective study of 28 cases: cholecystoduodenostomy performed with endoscopic gastrointestinal anastomosis stapling equipment. J Am Anim Hosp Assoc. 2008;44(1):10-18.

31. Center SA, Randolph JF, Warner KL, et al. Bacterial culture and immunohistochemical detection of bacteria and endotoxin in cats with suppurative cholangitis-cholangiohepatitis syndrome. J Am Vet Med Assoc. 2022;260:194-211.

32. Pillai S, Center SA, McDonough SP, et al. Ductal plate malformation in the liver of Boxer dogs: clinical and histological features. Vet Pathol. 2016;53(3):602-613.

33. Day MJ, Mansell J, Wilcock B, et al. Histopathological standards for the diagnosis of gastrointestinal inflammation in endoscopic biopsy samples from the dog and cat: a report from the World Small Animal Veterinary Association Gastrointestinal Standardization Group. J Comp Pathol. 2008;138(suppl 1):S1-S43.

34. Green J, Better OS. Systemic hypotension and renal failure in obstructive jaundice-mechanistic and therapeutic aspects. J Am Soc Nephrol. 1995;5(11):1853-1871.

35. Stewart L, Pellegrini CA, Way LW. Cholangiovenous reflux pathways as defined by corrosion casting and scanning electron microscopy. Am J Surg. 1988;155(1):23-28.

36. Center SA, Baldwin BH, Dillingham S, Erb HN, Tennant BC.
Diagnostic value of serum gamma-glutamyl transferase and alkaline phosphatase activities in hepatobiliary disease in the cat. J Am Vet Med Assoc. 1986;188(5):507-510.

37. Center SA, Warner K, Corbett J, Randolph JF, Erb HN. Proteins invoked by vitamin $\mathrm{K}$ absence and clotting times in clinically ill cats. J Vet Intern Med. 2000;14(3):292-297.

38. Britt RB, Brown JN. Characterizing the severe reactions of parenteral vitamin K1. Clin Appl Thromb Hemost. 2018;24(1):5-12.

39. Mooney ET, Agostini G, Griebsch C, Hickey M. Intravenous vitamin $\mathrm{K} 1$ normalises prothrombin time in 1 hour in dogs with anticoagulant rodenticide toxicosis. Aust Vet J. 2020;98(6):225-231.

40. Mi YN, Ping NN, Xiao X, Zhu Y-B, Liu J, Cao Y-X. The severe adverse reaction to vitamin $\mathrm{k} 1$ injection is anaphylactoid reaction but not anaphylaxis. PLoS One. 2014;9(3):e90199. doi:10.1371/journal.pone.0090199

41. Weiss DJ, Gagne JM, Armstrong PJ. Relationship between inflammatory hepatic disease and inflammatory bowel disease, pancreatitis, and nephritis in cats. J Am Vet Med Assoc. 1996;209(6):1114-1116.

42. Szabo G, Bala S, Petrasek J, Gattu A. Gut-liver axis and sensing microbes. Dig Dis. 2010;28(6):737-744.

43. Son $G$, Kremer M, Hines IN. Contribution of gut bacteria to liver pathobiology. Gastroenterol Res Pract. 2010;2010:453563. doi:10.1155/2010/453563

44. Sung JY, Olson ME, Leung JWC, et al. The sphincter of Oddi is a boundary for bacterial colonisation in the feline biliary tract. Microb Ecol Health Dis. 1990;3(4):199-207.

45. Sung JY, Shaffer EA, Olson ME, Leung JW, Lam K, Costerton JW. Bacterial invasion of the biliary system by way of the portal-venous system. Hepatology. 1991;14(2):313-317.

46. Slocum MM, Sittig KM, Specian RD, Deitch EA. Absence of intestinal bile promotes bacterial translocation. Am Surg. 1992:58(5):305-310.

47. Navaneethan U, Jayanthi V, Mohan P. Pathogenesis of cholangitis in obstructive jaundice-revisited. Minerva Gastroenterol Dietol. 2011;57(1):97-104.

48. Crouch JE. External and internal anatomy of the esophagus, stomach, duodenum and pancreas. In: Text-Atlas of Cat Anatomy. Lea \& Febiger; 1969:144-145.

49. Clements WDB, Parks R, Erwin P, Halliday MI, Barr J, Rowlands BJ. Role of the gut in the pathophysiology of extrahepatic biliary obstruction. Gut. 1996;39(4):587593.

50. Hofmann AF, Eckmann L. How bile acids confer gut mucosal protection against bacteria. PNAS. 2006;103(12):4333-4334.

51. Mantis NJ, Rol N, Corthesy B. Secretory IgA's complex roles in immunity and mucosal homeostasis in the gut. Mucosal Immunol. 2011;4(6):603-611.

52. Yamada T, Matsuda M, Ashida Y, et al. Isolation of secretory IgA from feline bile and bile IgA levels in growing cats. J Vet Med Sci. 1992;54(4):717-721.

53. Orlans E, Peppard JV, Payne AW, et al. Comparative aspects of the hepatobiliary transport of IgA. Ann N Y Acad Sci. 1983:409:411-427.

54. Van Bossuyt H, De Zanger RB, Wisse E. Cellular and subcellular distribution of injected lipopolysaccharide in rat liver and its inactivation by bile salts. J Hepatol. 1988;7(3):325-337.

55. Katz S, Grosfeld JL, Gross K, et al. Impaired bacterial clearance and trapping in obstructive jaundice. Ann Surg. 1984;199(1):14-20.

56. Seki E, De Minicis S, Osterreicher $\mathrm{CH}$, et al. TLR-4 enhances TGF-beta signaling and hepatic fibrosis. Nat Med. 2007:13(11):1324-1332.

57. Scott-Conner CEH, Grogan JB. The pathophysiology of biliary obstruction and its effect on phagocytic and immune function. J Surg Res. 1994;57(2):316-336.

58. Sung JY, Costerton JW, Shaffer EA. Defense system in the biliary tract against bacterial infection. Dig Dis Sci. 1992;37(5):689-696.

59. Raper SE, Barker ME, Jones AL, Way LW. Anatomic cor- 
relates of bacterial cholangiovenous reflux. Surgery. 1989;105(3):352-358

60. Sung JY, Leung JWC, Shaffer EA, Lam K, Olson ME, Costerton JW. Ascending infection of the biliary tract after surgical sphincterotomy and biliary stenting. J Gastroenterol Hepatol. 1992;7(3):240-245.

61. Sung JY, Leung JW, Olson ME, Lundberg MS, Costerton JW. Demonstration of transient bacterobilia by foreign body implantation in feline biliary tract. Dig Dis Sci. 1991;36(7):943948.

62. Trotman BW. Pigment gallstone disease. Gastroenterol Clin North Am. 1991;20(1):111-126.

63. Stewart HL, Lieber MM. Ligation of the common bile duct in the cat. Arch Pathol (Chic). 1935;19:34-36.

64. Center SA, Castleman W, Roth L, Baldwin BH, Tennant BC. Light microscopic and electron microscopic changes in the livers of cats with extrahepatic bile duct obstruction. Am J Vet Res. 1986;47(6):1278-1282.

65. Kaufman HS, Magnuson TH, Lillemoe K, Frasca P, Pitt $\mathrm{HA}$. The role of bacteria in gallbladder and common duct stone formation. Ann Surg. 1989;209(5):584-591.

66. Maurer KJ, Carey MC, Fox JG. Roles of infection, inflammation, and the immune system in cholesterol gallstone formation. Gastroenterology. 2009;136(2):425-440.

67. Stewart L, Griffiss JM, Jarvis GA, Way LW. Biliary bacterial factors determine the path of gallstone formation. $A m \mathrm{~J}$ Surg. 2006;192(5):598-603.

68. Stewart L, Griffiss JM, Jarvis GA, Way LW. Gallstones containing bacteria are biofilms: bacterial slime production and ability to form pigment solids determines infection severity and bacteremia. J Gastrointest Surg. 2007;11(8):977-984.

69. Stewart L, Griffiss JM, Jarvis GA, Way LW. Bacteria entombed in the center of cholesterol gallstones induce fewer infectious manifestations than bacteria in the matrix of pigment stones. J Gastrointest Surg. 2007;11(10):1298-1308.

70. Stewart L, Oesterle AL, Erdan L, Griffiss JM, Way LW. Pathogenesis of pigment gallstones in Western societies: the central role of bacteria. J Gastrointest Surg. 2002;6(6):891-904.

71. Swidsinski A, Lee SP. The role of bacteria in gallstone pathogenesis. Front Biosci. 2001;6:E93-E103.

72. van Geffen C, Savary-Bataille K, Chiers K, Giger U, Daminet S. Bilirubin cholelithiasis and haemosiderosis in an anaemic pyruvate kinase-deficient Somali cat. J Small Anim Pract. 2008;49(9):479-482.

73. Harvey AM, Holt PE, Barr FJ, Rizzo F, Tasker S. Treatment and long-term follow-up of extrahepatic biliary obstruction with bilirubin cholelithiasis in a Somali cat with pyruvate kinase deficiency. J Feline Med Surg. 2007;9(5):424-431.

74. Elwood CM, White RN, Freeman K, White M. Cholelithiasis and hyperthyroidism in a cat. $J$ Feline Med Surg. 2001;3(4):247-252.

75. Stewart L, Smith AL, Pellegrini CA, Motson RW, Way LW. Pigment gallstones form as a composite of bacterial microcolonies and pigment solid. Ann Surg. 1987;206(3):242-250.

76. Leung JWC, Sung JY, Costerton JW. Bacteriological and electron microscopy examination of brown pigment stones. J Clin Microbiol. 1989;27(5):915-921.

77. Maki T. Pathogenesis of calcium bilirubinate gallstone: role of $E$. coli, $\beta$-glucuronidase and coagulation by inorganic ions, polyelectrolytes and agitation. Ann Surg. 1966;164(1):90-100.

78. Siddiqui FG, Memon AA, Abro AH, Sasoli NA, Ahmad L. Routine histopathology of gallbladder after elective cholecystectomy for gallstones: waste of resources or a justified act? BMC Surg. 2013;13:26. doi:10.1186/1471-2482$13-26$

79. Salari B, Rezaee N, Toland A, Chatterjee D. Follicular cholecystitis: clinicopathologic associations. Hum Pathol. 2019;88:1-6. doi:10.1016/j.humpath.2019.03.003

80. Tsui WMS, Lam PWY, Lee W-K, Chan Y-K. Primary hepatolithiasis, recurrent pyogenic cholangitis, and oriental chol- angiohepatitis - a tale of 3 countries. Adv Anat Pathol. 2011;18(4):318-328.

81. Tazuma S. Epidemiology, pathogenesis, and classification of biliary stones (common bile duct and intrahepatic). Best Pract Res Clin Gastroenterol. 2006;20(6):1075-1083.

82. van Brummelen SE, Venneman NG, van Erpecum KJ, VanBerge-Henegouwen GP. Acute idiopathic pancreatitis: does it really exist or is it a myth? Scand J Gastroenterol Suppl. 2003;239:117-122.

83. Elta GH. Sphincter of Oddi dysfunction and bile duct microlithiasis in acute idiopathic pancreatitis. World J Gastroenterol. 2008;14(7):1023-1026.

84. Saraswat VA, Sharma BC, Agarwal DK, Kumar R, Negi TS, Tandon RK. Biliary microlithiasis in patients with idiopathic acute pancreatitis and unexplained biliary pain: response to therapy. J Gastroenterol Hepatol. 2004;19(10):1206-1211.

85. Gerke H, Baillie J. Biliary microlithiasis: a neglected cause of recurrent pancreatitis and biliary colic. J Gastroenterol Hepatol. 2005;20(4):499-501.

86. Venneman NG, Buskens $E$, Besselink MGH, et al. Small gallstones are associated with increased risk of acute pancreatitis: potential benefits of prophylactic cholecystectomy. Am J Gastroenterol. 2005;100(11):2540-2550.

87. Desmet VJ. Congenital diseases of intrahepatic bile ducts: variations on the theme "ductal plate malformation". Hepatology. 1992;16(4):1069-1083.

88. Wills ES, Roepman R, Drenth JPH. Polycystic liver disease: ductal plate malformation and the primary cilium. Trends Mol Med. 2014;20(5):261-270.

89. Masyuk T, Masyuk A, LaRusso N. Cholangiociliopathies: genetics, molecular mechanisms, and potential therapies. Curr Opin Gastroenterol. 2009;25(3):265-271.

90. Gunay-Aygun M, Avner ED, Bacallao RL, et al. Autosomal recessive polycystic kidney disease and congenital hepatic fibrosis: summary statement of a first National Institutes of Health/Office of Rare Diseases Conference. J Pediatr. 2006;149(2):159-164.

91. Desmet VJ. Pathogenesis of ductal plate abnormalities. Mayo Clin Proc. 1998;73(1):80-89.

92. Desmet VJ. What is congenital hepatic fibrosis? Histopathology. 1992;20(6):465-477.

93. Srinath A, Shneider BL. Congenital hepatic fibrosis and autosomal recessive polycystic kidney disease. J Pediatr Gastroenterol Nutr. 2012;54(5):580-587.

94. Drenth JPH, Chrispijn M, Bergmann C. Congenital fibrocystic liver diseases. Best Pract Res Clin Gastroenterol. 2010;24(5):573-584.

95. Suchy FJ. Caroli disease. UpToDate. Accessed June 16, 2020. https://www.uptodat.com/contents/caroli-disease

96. Seibert LM, Center SA, Randolph JF, et al. Relationships between congenital peritoneopericardial diaphragmatic hernia or congenital central diaphragmatic hernia and ductal plate malformations in dogs and cats. J Am Vet Med Assoc. 2021;259(9):1009-1024.

97. Center SA, Warner KL, Erb HN. Liver glutathione concentrations in dogs and cats with naturally occurring liver disease. Am J Vet Res. 2002;63(8):1187-1197.

98. Center SA, Randolph JF, Warner KL, et al. The effects of $S$-adenosylmethionine on clinical pathology and redox potential in the red blood cell, liver, and bile of clinically normal cats. J Vet Intern Med. 2005;19(3):303-314.

99. Center SA. Metabolic, antioxidant, nutraceutical, probiotic, and herbal therapies relating to the management of hepatobiliary disorders. Vet Clin North Am Small Anim Pract. 2004;34(1):67-172, vi.

100. Sokol RJ. Fat-soluble vitamins and their importance in patients with cholestatic liver diseases. Gastroenterol Clin North Am. 1994;23(4):673-705.

101. Sokol RJ, Butler-Simon NA, Bettis D, Smith DJ, Silverman A. Tocopheryl polyethylene glycol 4000 succinate therapy for vitamin E deficiency during chronic childhood cholestasis: neurologic outcome. J Pediatr. 1987;111(6 pt 1):830-836 
102. Wang X, Quinn PJ. Vitamin E and its function in membranes. Prog Lipid Res. 1999;38(4):309-336.

103. Gille L, Staniek K, Rosenau T. Tocopheryl quinones and mitochondria. Mol Nutr Food Res. 2010;54(5):601-615.

104. Traber MG. Vitamin E and $\mathrm{K}$ interactions-a 50-year-old problem. Nutr Rev. 2008;66(11):624-629.

105. Corrigan JJ. Coagulation problems relating to vitamin $\mathrm{E}$. Am J Pediatr Hematol Oncol. 1979;1(2):169-173.

106. Fickert P, Pollheimer MJ, Silbert D, et al. Differential effects of norUDCA and UDCA in obstructive cholestasis in mice. J Hepatol. 2013;58(6):1201-1208.

107. Poupon R. Ursodeoxycholic acid and bile-acid mimetics as therapeutic agents for cholestatic liver diseases: overview of their mechanisms of action. Clin Res Hepatol Gastroenterol. 2012;36(suppl 1):S3-S12.

108. Güldütuna S, Zimmer G, Imhof M, Bhatti S, You T, Leuschner U. Molecular aspects of membrane stabilization by ursodeoxycholate. Gastroenterology. 1993;104(6):1736-1744.

109. Rodrigues CM, Fan G, Wong PY, Kren BT, Steer CJ. Ursodeoxycholic acid may inhibit deoxycholic acid-induced apoptosis by modulating mitochondrial transmembrane potential and reactive oxygen species production. Mol Med. 1998;4(3):165-178.

110. Mitsuyoshi H, Nakashima T, Sumida $Y$, et al. Ursodeoxycholic acid protects hepatocytes against oxidative injury via induction of antioxidants. Biochem Biophys Res Commun. 1999;263(2):537-542.

111. Ljubuncic P, Tanne Z, Bomzon A. Ursodeoxycholic acid suppresses extent of lipid peroxidation in diseased liver in experimental cholestatic liver disease. Dig Dis Sci. 2000;45(10):1921-1928.

112. Rodríguez-Ortigosa CM, Cincu RN, Sanz S, Ruiz F, Quiroga J, Prieto J. Effect of ursodeoxycholic acid on methionine adenosyltransferase activity and hepatic glutathione metabolism in rats. Gut. 2002;50(5):701-706.

113. Bernstein C, Payne CM, Bernstein H, H Garewal H. Activation of the metallothionein IIA promoter and other key stress response elements by ursodeoxycholate in HepG2 cells: relevance to the cytoprotective function of ursodeoxycholate. Pharmacology. 2002;65(1):2-9.

114. Lapenna D, Ciofani G, Festi D, et al. Antioxidant properties of ursodeoxycholic acid. Biochem Pharmacol. 2002;64(11):1661-1667.

115. Kawata K, Kobayashi Y, Souda K, et al. Enhanced hepatic Nrf2 activation after ursodeoxycholic acid treatment in patients with primary biliary cirrhosis. Antioxid Redox Signal. 2010;13(3):259-268.

116. Arisawa S, Ishida K, Kameyama N, et al. Ursodeoxycholic acid induces glutathione synthesis through activation of PI3K/Akt pathway in HepG2 cells. Biochem Pharmacol. 2009;77(5):858-866.

117. Okada K, Shoda J, Taguchi K, et al. Ursodeoxycholic acid stimulates Nrf2-mediated hepatocellular transport, detoxification, and antioxidative stress systems in mice. Am J Physiol Gastrointest Liver Physiol. 2008;295(4):G735G747.

118. Sasatomi K, Noguchi K, Sakisaka S, Sata M, Tanikawa K. Abnormal accumulation of endotoxin in biliary epithelial cells in primary biliary cirrhosis and primary sclerosing cholangitis. J Hepatol. 1998;29(3):409-416.

\section{Supplementary Materials}

Supplementary materials are available online at the journal website: avmajournals.avma.org 